\title{
CONCEITOS-CHAVE, LEGISLAÇÕES E NORMAS AMBIENTAIS FUNDAMENTAIS PARA A COMPREENSÃO DAS CONSEQUÊNCIAS SOCIOECONÔMICAS E AMBIENTAIS DA INSTALAÇÃO DE PARQUES EÓLICOS
}

\begin{abstract}
Oziel de Medeiros Pontes
Pedro Vieira de Azevedo

https://doi.org/10.15628/geoconexoes.2019.8942

\section{RESUMO}

O artigo discute conceitos-chave, legislações e normas ambientais fundamentais para a compreensão das consequências socioeconômicas e ambientais dos parques eólicos em comunidades locais. Por se tratar de um artigo de revisão de literatura, baseia-se no levantamento da narrativa de literatura em torno desse arcabouço conceitual, jurídico e legislativo. Logo, ao se levar em consideração tais referenciais conceituais e jurisprudenciais, os resultados evidenciaram a sua relevância no que se refere à análise de possíveis interferências sociais, econômicas e ambientais dos parques eólicos em comunidades locais, algo que põe em evidência a necessidade de investigações mais profundas sobre a relação entre a base conceitual e jurídico-normativa para a apreensão dos produtos socioeconômicos e ambientais em comunidades locais a partir da instalação, funcionamento e operação dos parques eólicos.
\end{abstract}

Palavras-chave: Conflitos ambientais. Justiça ambiental. Licenciamento ambiental no Brasil. Avaliação de equidade ambiental. Comunidade e tutela do meio ambiente. Legislações e normas ambientais.

\section{ABSTRACT}

The article discusses key concepts, law and fundamental environment regulations to understand the socioeconomic and environmental consequences of the wind farm in local communities. As it is a literature review article, it is based on the literature narrative around this conceptual, juridical and legislative framework. Therefore, when it takes into account such conceptual and jurisprudential references, the results highlighted its relevance in relation to the analysis of possible social, economic and environmental interferences of the wind farms in local communities, something that highlights the necessity of deepen investigations about the relation between conceptual and legal normative basis for the seizure of socioeconomic and environmental products in local communities from the wind farms installation, functioning and operation.

Keywords: Environmental Conflicts. Environmental justice. Environmental license in Brazil. Environmental equity evaluation. Environment community and tutelage. Law and Standards. 


\section{INTRODUÇÃO}

Proveniente das discussões das reuniões globais sobre meio ambiente e fator importante na manutenção da crise ecológica, a dialógica presente na noção de desenvolvimento sustentável, congrega, ao mesmo tempo, a poluição, subproduto do desenvolvimento, e a proteção do meio ambiente, presente na ideia de sustentabilidade (MORIN, 2003). Em suma, aponta para a melhoria da qualidade de vida das sociedades, principalmente nos países desenvolvidos, e traz consigo a possibilidade de um desequilíbrio ambiental.

Por sua vez, Enrique Leff (2006) é contra a correspondência entre desenvolvimento e meio ambiente. Tal raciocínio se aproxima das ideias de Edgar Morin, visto que esse defende a contradição entre o crescimento econômico e a poluição num contexto futuro incerto. No entanto, Leff (2006) é a favor do desenvolvimento sustentável que insere a economia na ecologia e na cultura, além de limitar o crescimento econômico ao consumismo. Portanto, a economia e a ecologia são conceitos complementares para esse autor.

A esse respeito, Lester Brown (1981) destaca a ideia de que uma sociedade sustentável é aquela que satisfaz suas necessidades sem diminuir as perspectivas das gerações futuras. Em outras palavras, qualquer desenvolvimento que se preze deve levar em consideração o futuro da humanidade.

Para Baracuhy (2001), o objetivo é usar o meio ambiente somente com finalidades que estejam dentro de suas possibilidades, que possam superar as suas causas de instabilidade. Por conseguinte, o uso e o manejo dos recursos naturais do nosso planeta têm sido manipulados pela humanidade com pouca sabedoria e precaução.

Nesse sentido, existem relações criadas pelo capitalismo e a destruição da vida no planeta, o que produz a separação entre a sociedade e natureza, além da transformação das pessoas e das coisas em mercadorias, efetuando a coisificação dos seres humanos e a adoração aos objetos de consumo, chamado de fetichismo (MARX, 2006). Em suma, a capitalização da natureza provoca a destruição dos ecossistemas planetários, o que produz fatores responsáveis pela crise ambiental.

Para Goldshimith et al. (1972), o desenvolvimento sustentável acontece quando as metas e objetivos de uma dada sociedade podem ser continuamente atendidos. Para Pronk e ul Haq (1992), a sustentabilidade existe quando o crescimento econômico proporciona justiça e igualdade para todos os seres humanos, sem a degradação dos recursos naturais finitos nem tão pouco o desrespeito aos limites de carga do sistema. Portanto, enquanto Goldshimith et al. (1972) definem o desenvolvimento sustentável pela satisfação ótimas das pessoas, Pronk e ul Haq (1992) concentram-no no crescimento econômico.

Para Constanza (1991), o conceito de desenvolvimento sustentável deve levar em consideração que o sistema econômico é um subsistema do sistema ecológico, sistema ecológico que apresenta uma taxa de mudança mais lenta. Dito de outro modo, para ser sustentável, o desenvolvimento precisa manter as atividades humanas dentro de limites estabelecidos pelo sistema ecológico. Já para Munasinghe e McNeely (1995) a sustentabilidade diz respeito à obtenção da manutenção e do crescimento no tempo de um conjunto de indicadores que promova o bem-estar social. 
Por seu turno Capra (2006) defende que a Economia Clássica apregoa um crescimento econômico que incrementa a produção e o consumo do setor privado e o direciona apenas para a esfera da tecnologia, da produtividade e do lucro. Esse dogma econômico acredita que o crescimento econômico aumenta as oportunidades das classes pobres terem acesso às sobras das riquezas materiais em seu benefício, ao passo que a realidade mostra que o crescimento da economia em muitos países não reduziu as desigualdades sociais e o desemprego, além de aumentar os danos ao meio ambiente.

Assim:

[...] Excessiva dependência da energia e dos recursos naturais e excessivo investimento em capital, em vez de trabalho, são altamente inflacionários e acarretam desemprego maciço. (CAPRA, 2006, p. 221, grifo nosso).

A tecnologia atual é usada a partir do seu potencial para a resolução de problemas práticos da humanidade, a qual é pesada, masculina e consumidora de recursos, enquanto a humanidade necessita de uma mudança na natureza dos valores que fundamentem em direção à tecnologia mais branda, que estimule a cooperação, a distribuição de renda mais justa, a resolução de conflitos, os acordos sociais, a redistribuição de riqueza e o crescimento interior (CAPRA, 2006). Logo, devemos lutar por uma tecnologia mais humana e menos utilitarista e pragmática.

Para Capra (2006), inseparável do crescimento econômico e tecnológico, outro fator importante para a degradação ambiental e o aumento da demanda por energia reside no crescimento das instituições, tais como pequenas empresas e sociedades anônimas até universidades, igrejas, cidades, governos e nações. Nesse caso, a marca da impessoalidade e a alienação são características dessas instituições, levando as pessoas a ter que lidar com as mesmas a serem exploradas e despersonalizadas (CAPRA, 2006).

Além disso, Capra (2006) diz que esses empreendimentos econômicos grandes desvalorizam as profissões menos qualificadas, gerando aumento do desemprego, enquanto as pequenas e médias empresas, com o uso intensivo de mão-de-obra, criam mais empregos e produzem custos socioambientais e econômicos menores.

Nesse sentido, o atual modelo de desenvolvimento sustentável dá provas de não estar de acordo com as limitações da ecologia nem dos recursos naturais. Desse modo, qualquer modelo de desenvolvimento sustentável a expansão do bem-estar para as nações subdesenvolvidas, sem esquecer-se da diminuição da produção e consumo de bens materiais (JACKSON, 2013). Portanto, urge uma prosperidade sem crescimento, isto é, uma repartição da riqueza e consumo aos mais pobres, levando em consideração os limites do meio ambiente (JACKSON, 2013). Além disso, a prosperidade transcende preocupações materiais, porque tem a ver com a nossa qualidade de vida, saúde e felicidade de nossas famílias, vitalidade de nossos relacionamentos, coesão comunitária, satisfação no trabalho e significados partilhados e duradouros, dependendo da participação social em plenitude (JACKSON, 2013).

Nesse contexto, a crítica a "religião do crescimento" é importante, isto é, a ideia de que o crescimento econômico irá resolver todos os problemas e o combate ao consumismo, porém o 
conceito de decrescimento não pode ser quantitativo, visto que algumas atividades devem ser não apenas reduzidas, mas suprimidas, tais como a publicidade, a energia atômica e o carvão, enquanto outras necessitam da redução, como a circulação de automóveis, ou incremento, como a geração de energias alternativas, educação, saúde e a agricultura biológica (LÖWY, 2015). Em outras palavras, existem várias coisas que se requer a expansão, outras a redução e outras a supressão (LÖWY, 2015).

Diante disso, embora Löwy (2015) acerte ao creditar méritos a Jackson (2013) pelo combate ao fanatismo do crescimento econômico e consumismo, no que se refere ao incremento ininterrupto de atividades tidas como ideais para o desenvolvimento humano, o mesmo não pode ser dito em relação à compreensão de que tais atividades são perfeitas e não ocasionam consequências econômicas e socioambientais aos setores mais vulneráveis da sociedade. Isso é verificado no que tange aos efeitos socioeconômicos e ambientais dos parques eólicos para certos segmentos sociais de comunidades em diversas partes do mundo.

Da mesma forma, ao contrário da visão unidirecional de Löwy (2015) no que se refere à redução da circulação de automóveis, que também é importante para o desenvolvimento das sociedades, principalmente no combate à poluição do ar e congestionamentos nos grandes centros urbanos, outros fatores também assumem um importância vital, tais como, por exemplo, o incentivo à cidadania participativa, a qual poderá influenciar não apenas a diminuição na frota de veículos, mas a adoção de carros elétricos, reforço dos laços econômico-comerciais comunitários e adoção do teletrabalho. Então, para o desenvolvimento humano, a redução quantitativa per si de algumas atividades não trará ganhos reais, porque as mudanças deverão ser de ordem qualitativa, cujas decisões que as antecedem deverão ser submetidas ao crivo da maioria da sociedade civil organizada. Nesse sentido, Jackson (2013) tem razão ao defender um sentido comum e colaborativo à existência social.

Este trabalho, por meio de uma revisão da literatura, objetiva analisar conceitos, legislações e normas, os quais são fundamentais para a compreensão das consequências socioeconômicas e ambientais de parques eólicos. Nesse sentido, o artigo está estruturado na revisão do arcabouço conceitual sobre Conflitos e Justiça Ambiental, Licenciamento Ambiental no Brasil, Avaliação de Equidade Ambiental e Comunidade e Tutela do Meio Ambiente. Além disso, referente às legislações e normas, optou-se pela análise de trechos da Constituição, Decreto Lei 99.274/1990, Lei nº 6.938/1981, Lei complementar $n^{\circ}$ 140/2011, Medida Cautelar na Ação Direta de Inconstitucionalidade $n^{\circ} 3.540 / 2005$, Resolução n 9/1987 e Resolução $n^{\circ}$ 237/1997. Ao final, as conclusões indicam ilações do tema com base em perspectivas novas e reflexões acerca de lacunas e questões para a investigação e ações relevantes ao tema.

\section{CONFLITOS E JUSTIÇA AMBIENTAL}

Injustiça ambiental foi a terminologia consagrada para denominar o fenômeno de imposição desproporcional dos riscos ambientais às populações menos favorecidas, tomando por base estudos que evidenciaram que a distribuição dos riscos ambientais, nos estados Unidos, não se fazia de modo 
aleatório, mas acompanhava a distribuição territorial das populações de baixa renda e dos grupos étnicos; como contraponto, tem-se a ideia de Justiça Ambiental, que seria alcançada em sendo o quadro de injustiça superado (ACSELRAD et al., 2009).

Nos Estados Unidos, na década de 1980, constituiu-se o Movimento de Justiça Ambiental, refletindo uma associação criativa entre lutas de caráter social, territorial, ambiental e de direitos civis, o qual veio a se consolidar como uma grande rede, inclusive de caráter internacional, articuladora de várias entidades e grupos para o enfrentamento do chamado racismo ambiental, impulsionando uma reflexão geral sobre as relações entre risco ambiental, pobreza e etnicidade (ACSELRAD et al. 2009, p. 17-25).

No Brasil, houve uma ampliação do escopo do conceito de Justiça Ambiental, "de modo a ultrapassar meramente as questões raciais e de localização de riscos provenientes de origem química presentes no debate norte-americano" (CARTIER et al., 2009, p. 2.695). Assim, no país, por Justiça Ambiental "entende-se a condição de existência social em que se verifica igual proteção aos distintos grupos sociais com relação aos danos ambientais" (ACSELRAD, 2011, p. 47).

Dessa forma, tendo por base a existência da sociodiversidade para a caracterização do meio social, surgem diversos atores sociais da sociedade civil e do Estado que possuem inúmeras motivações para a sua atuação na geração de conflitos sociais: interesses, valores, necessidades, aspirações, ocupação do mesmo território, entre outros. Nesse sentido, na área ambiental, os conflitos estão associados à escassez e ao comprometimento da qualidade ambiental por intermédio do controle e uso indiscriminado de recursos ambientais limitados por determinados atores sociais (QUINTAS, 2006).

Desse modo, a partir da constatação de que a proteção ambiental é desigual, e de que existe uma maior exposição das populações vulneráveis aos males ambientais embutidos nos projetos de desenvolvimento, surgem as demandas por Justiça Ambiental. Constata-se ainda que os conflitos são inerentes aos meios sociais humanos, sendo importante a regulamentação desses conflitos, isto é, a mediação dos mesmos por meio de regras e limites aceitos pela coletividade, já que não há a menor condição da sua resolução completa nem a possibilidade da sua não existência (BOBBIO, 1992).

Assim:

Entretanto, esses atores, ao tomarem suas decisões, nem sempre levam em conta os interesses e necessidades das diferentes camadas sociais direta ou indiretamente afetadas. As decisões tomadas podem representar benefícios para uns e prejuízos para outros. Um determinado empreendimento pode representar lucro para empresários, emprego para trabalhadores, conforto pessoal para moradores de certas áreas, votos para políticos, aumento de arrecadação para Governos, melhoria da qualidade de vida para parte da população e, ao mesmo tempo, implicar prejuízo para outros empresários, desemprego para outros trabalhadores, perda de propriedade, empobrecimento dos habitantes da região, ameaça à biodiversidade, erosão, poluição atmosférica e hídrica, desagregação social e outros problemas que caracterizam a degradação ambiental. (QUINTAS, 2006, p. 31). 
Nessa questão, conforme cada caso em particular, urge a gestão ambiental à construção, revisão, adoção e/ou aplicação de políticas públicas ambientais condizentes com a inserção dos atores sociais envolvidos em conflitos ambientais. Portanto, a gestão ambiental que vise o bem comum, e não simplesmente a disputa de interesses no âmbito privado, deverá ter como base a busca da Justiça Ambiental e formas menos destrutivas desses conflitos para os referidos atores, cabendo ao Poder Público a função de defesa dos interesses coletivos através da proposição de soluções para a redução de conflitos e injustiças ambientais, restrita às limitações impostas pela lei e/ou ao seu aprimoramento em função da participação democrática dos vários segmentos sociais com a finalidade do atendimento ao bem comum.

\section{LICENCIAMENTO AMBIENTAL NO BRASIL}

No que se refere ao Licenciamento Ambiental no Brasil, o exercício de atividade econômica no país é livre, independentemente de autorização de órgãos públicos, salvo nos casos previstos em lei, de acordo com o artigo 170, parágrafo único (BRASIL, 2012). Da mesma forma, a par do artigo 10 da Política Nacional do Meio Ambiente ou PNMA - lei $n^{\circ}$ 6.938/1981 - ocorre para empreendimentos e atividades utilizadores de recursos ambientais, considerados efetiva ou potencialmente poluidores, ou capazes, sob qualquer forma, de causar degradação ambiental, os quais dependerão de prévio licenciamento ambiental para construção, instalação, ampliação e funcionamento, o que significa que devem ser submetidos a uma análise e controle prévios por parte do poder público (BRASIL, 1981). Como bem alerta Milaré (2013), tal controle se faz necessário para a prevenção, correção, mitigação e/ ou compensação dos riscos e impactos ambientais.

O Licenciamento Ambiental é ação típica e indelegável do Poder Executivo, constituindo-se num importante instrumento de gestão ambiental na esfera pública, de acordo com o PNMA, no seu art. $9^{\circ}$, inciso IV, através do qual a administração pública procura exercer o necessário controle sobre as atividades humanas que interferem nas condições ambientais (BRASIL, 1981). Na forma trazida na lei complementar $n^{\circ} 140 / 2011$, vem a ser "o procedimento administrativo destinado a licenciar atividades ou empreendimentos utilizadores de recursos ambientais, efetiva ou potencialmente poluidores ou capazes, sob qualquer forma, de causar degradação ambiental" (BRASIL, 2011), pelo que deve ser precedido por estudos técnicos que subsidiem a sua análise conforme a Resolução CONAMA n² 237 , art. $1^{\circ}$, inciso III (BRASIL, 1997). No dizer de Milaré (2013, p. 778), "como todo procedimento tendem, todos, a um resultado final e conclusivo".

Tendo por escopo último a viabilização de uma gestão que garanta a qualidade ambiental e o equilíbrio ecológico, tal como preconizado pela $\mathrm{CF} / 88$, contemplou o Ordenamento Jurídico brasileiro o instituto da Avaliação de Impacto Ambiental (AIA), que se configura como um dos instrumentos da PNMA em seu art. $9^{\circ}$, inciso III (BRASIL, 1981).

0 art. $9^{\circ}$ da PNMA enumera treze instrumentos para viabilizar a execução da política ambiental no país, os quais, sob o ponto de vista técnico, podem ser classificados em dois grupos: $\left(1^{\circ}\right)$ grupo - 
instrumentos administrativos de comando e controle: (I) o estabelecimento de padrões de qualidade ambiental, (II) o zoneamento ambiental, (III) a avaliação de impactos ambientais, (IV) o licenciamento e a revisão de atividades efetiva ou potencialmente poluidoras, $(\mathrm{VI})$ a criação de espaços territoriais especialmente protegidos pelo poder público federal, estadual e municipal, tais como áreas de proteção ambiental, de relevante interesse ecológico e reservas extrativistas, (VII) o sistema nacional de informações sobre o meio ambiente, (VIII) o Cadastro Técnico Federal de Atividades e Instrumentos de Defesa Ambiental, (IX) as penalidades disciplinares ou compensatórias ao não cumprimento das medidas necessárias à preservação ou correção da degradação ambiental, $(X)$ a instituição do Relatório de Qualidade do Meio Ambiente, a ser divulgado anualmente pelo Instituto Brasileiro do Meio Ambiente e dos Recursos naturais Renováveis - IBAMA, (XI) a garantia da prestação de informações relativas ao meio ambiente, obrigando-se o poder público a produzi-las, quando inexistentes e (XII) o Cadastro Técnico Federal de atividades potencialmente poluidoras e utilizadoras dos recursos ambientais; $\left(2^{\circ}\right)$ grupo - instrumentos econômicos de gestão ambiental: (V) os incentivos à produção e instalação de equipamentos e a criação ou absorção de tecnologia, voltados para a melhoria da qualidade ambiental e (XIII) os instrumentos econômicos, como concessão florestal, servidão ambiental, seguro ambiental e outros (BRASIL, 1981).

A legislação regulamentadora da PNMA ou dec. 99.274/1990 vinculou a AIA aos sistemas de licenciamento, pelo que, no caso de Licenciamento Ambiental, tem-se como indispensável a AIA, isto é, uma avaliação técnica e prévia - vale dizer, a priori e não a posteriori - dos riscos e danos potenciais que determinado empreendimento ou ação pode causar às características essenciais do meio, seus recursos e seu equilíbrio ecológico (MILARÉ, 2013).

Corroborando tal assertiva, Leuzinger e Cureau (2013) afirmam que a AIA consiste numa das melhores estratégias para a prevenção de danos ambientais, tanto nos casos em que existe certeza científica acerca dos efeitos de determinada atividade, quanto naqueles em que ainda não se tem exata dimensão dos danos que possa vir a causar, embora exista fundado receio de que possa acarretar consequências severas ao ambiente.

A mesma normativa, instituída pelo Decreto Lei 99.274/1990, outorgou ao Conselho Nacional do Meio Ambiente (CONAMA) competência para fixar os critérios básicos segundo os quais serão exigidos estudos de impacto ambiental para fins de licenciamento, expresso no art. $18, \S 1^{\circ}$, com poderes, para tanto, de editar as resoluções que entender necessárias, no art. 48 (BRASIL, 1990a).

Ao fazer uso da referida competência, o CONAMA expediu a Resolução n²37/1997, a qual deixou claro, logo no art. $1^{\circ}$, inciso III, que a AIA, que ela chama de estudos ambientais, é gênero, de que são espécies todos e quaisquer estudos relativos aos aspectos ambientais apresentados como subsídio para a análise da Licença Ambiental, tais como: relatório ambiental, plano e projeto de controle ambiental, relatório ambiental preliminar, diagnóstico ambiental, plano de manejo, plano de recuperação de área degradada e análise preliminar de risco (MILARÉ, 2013).

É durante a AIA, enquanto momento prévio de verificação/definição, que se analisa que estudo ambiental se mostra apropriado para determinado licenciamento; em se tratando de atividade 
potencialmente causadora de significativa degradação, por força constitucional, inscrito no art. 225, $\S 1^{\circ}$, inciso IV, da CF/88, o estudo ambiental tem de ser o Estudo de Impacto Ambiental, com o seu respectivo relatório, o Relatório de Impacto Ambiental ou EIA/RIMA (BRASIL, 2012); ao contrário, se a atividade apenas modifica, de alguma forma, o meio, pode-se, observando o critério de adequação, fazer opção pelos outros estudos ambientais, o que é ratificado na resolução CONAMA n 237/1997, art. $3^{\circ}$ (BRASIL, 1997).

Todavia, não obstante o seu escopo de proteção ambiental, tem-se observado que a AIA acaba sendo servil a lógica de distribuição desigual dos males ambientais e os procedimentos convencionais de avaliação ambiental tendem a ser prisioneiros de concepções tecnicistas sobre a gestão do ambiente. Esse discurso gestionário considera um meio ambiente abstrato e passível de simples aplicação de dispositivos de racionalização (ACSELRAD, 2011).

Nesse sentido, em última análise, os investidores de projetos econômicos, conjuntamente com o poder público, preponderam uma preocupação com o que julgam como efetividade dos instrumentos, e desconsideram as dimensões sociológicas ou culturais do meio ambiente, apenas o consideram como sendo formado por pura matéria e energia, as quais necessariamente devem ser inseridas na lógica mercantilista global.

Porém, uma interpretação sistemática da legislação nacional, notadamente a partir do prisma constitucional, possibilita perceber que o meio ambiente possui uma conotação múltipla, tendo em vista a abrangência que contempla, e, a partir deste preceito, a doutrina ambiental (Milaré, 2013; Leuzinger e Cureau, 2013; Sirvinskas, 2009; Fiorillo, 2008; Silva, 2009) elenca o meio ambiente como integrado pelo meio ambiente natural, referindo-se aos bens ambientais naturais de origem biótica, tais como a flora e fauna, e abiótica, como é o caso do ar, água e solo; meio ambiente artificial, referindo-se a todas as criações provenientes da ação transformadora do homem, que se traduzem nas suas múltiplas obras, como, por exemplo, as edificações, as vias públicas; meio ambiente cultural, referindo-se às criações do espírito humano que são dotadas de especial valoração, como, por exemplo, um sítio arqueológico e meio ambiente do trabalho, que refere-se à manutenção da saúde e da segurança do trabalhador no local onde trabalha.

Nesse contexto, a Constituição Federal de 1988, em seu artigo 200 e inciso VIII, atribui competência ao Sistema Único de Saúde de "colaborar na proteção do meio ambiente, nele compreendido o do trabalho" (BRASIL, 2012, p. 118). Tal classificação, inclusive, é reconhecida pelo órgão de cúpula do Poder Judiciário no país, qual seja o Supremo Tribunal Federal (STF), como se observa na Medida Cautelar na Ação Direta de Inconstitucionalidade n³.540/DF (BRASIL, 2005).

De acordo com a Medida Cautelar na Ação Direta de Inconstitucionalidade n³.540/DF:

[...] A incolumidade do meio ambiente não pode ser comprometida por interesses empresariais nem ficar dependente de motivações de índole meramente econômica, ainda mais se se tiver presente que a atividade econômica, considerada a disciplina constitucional que a rege, está subordinada, dentre outros princípios gerais, àquele 
que privilegia a defesa do meio ambiente, expresso na CF, art. 170 e inciso VI, que traduz conceito amplo e abrangente das noções de meio ambiente natural, de meio ambiente cultural, de meio ambiente artificial (espaço urbano) e de meio ambiente laboral [...] (BRASIL, 2005, p. 2, grifo nosso).

De acordo com a CF/88, art. 216:

\begin{abstract}
Constituem patrimônio cultural brasileiro os bens de natureza material e imaterial, tomados individualmente ou em conjunto, portadores de referência à identidade, à ação, à memória dos diferentes grupos formadores da sociedade brasileira, nos quais se incluem: I - as formas de expressão; II - os modos de criar, fazer e viver; III - as criações científicas, artísticas e tecnológicas; IV - as obras, objetos, documentos, edificações e demais espaços destinados às manifestações artístico-culturais; $V$ os conjuntos urbanos e sítios de valor histórico, paisagístico, artístico, arqueológico, paleontológico, ecológico e científico. (BRASIL, 2012, p. 124).
\end{abstract}

A PNMA, no art. $3^{\circ}$, inciso I, conceitua de meio ambiente como sendo: "o conjunto de condições, leis, influências e interações de ordem física, química e biológica, que permite, abriga e rege a vida em todas as suas formas" (BRASIL, 1981, p. 16.509). Tal conceito, que é do ano de 1981, vale destacar, é considerado reduzido e limitado pela doutrina ambiental pós $\mathrm{CF} / 88$.

Desse modo, embora se privilegie os recursos naturais, o trato do patrimônio ambiental nacional nos indica que, ao se falar de bens ambientais, a mesma solicitude se dirige para outras sortes de bens (MILARÉ, 2013). Assim, pelo fato dos aludidos bens figurarem como produto específico da espécie humana, e recordarem sempre a presença do homem nos ecossistemas naturais e no habitat que é próprio da espécie, bem como porque a $\mathrm{CF} / 88$ estabelece como um dos objetivos para a proteção do bem ambiental a tutela da sadia qualidade de vida para todos, presente e futuras gerações, possibilitando-se compreender, a partir daí, que é a interação equilibrada dos elementos naturais, artificiais e culturais que propiciará tal (a sadia qualidade de vida). Nesse sentido, Silva (2009) também defende esse ponto de vista.

Por outro lado, a implantação de empreendimentos eólicos no Brasil, particularmente na região Nordeste, tem contribuído para que se facilite a liberação de licenças ambientais. Mais recentemente, existe uma pressão maior para que as exigências de Estudos de Impactos Ambientais (EIA) e de Relatórios de Impactos Ambientais (RIMA) sejam substituídos por estudos simplificados, como é o exemplo dos Relatórios Ambientais Simplificados ou RAS (SANTOS, 2014). A pressão dos investidores ou empreendedores tem contribuído para que ocorra a flexibilidade da legislação ambiental, sob o pretexto de que os empreendimentos eólicos são projetos de baixo impacto ambiental. 


\section{AVALIAÇÃO DE EQUIDADE AMBIENTAL}

Os movimentos por Justiça Ambiental sustentam ainda que os atuais mecanismos de avaliação ambiental, ao separarem o meio ambiente em meios físico, biológico e socioeconômico, desconsideram o entrelaçamento empírico entre esses meios, bem como as dinâmicas socioculturais de apropriação, uso e reprodução dos recursos ambientais (ACSELRAD, 2011). Assim, países influenciados por ações coletivas tenderam, em suas políticas públicas, a superar tais avaliações estritamente tecnicistas, introduzindo em todas as instâncias de planejamento a consideração da desigualdade social na distribuição dos danos e benefícios ambientais dos programas e projetos de desenvolvimento. Essa perspectiva é que orienta a denominada Avaliação de Equidade Ambiental (AEA).

A definição de AEA a identifica como um instrumento de promoção da Justiça Ambiental que visa fortalecer os movimentos e grupos sociais atingidos nos processos de licenciamento e tomada de decisão sobre empreendimentos que podem afetar seu modo de vida de forma direta ou indireta (ACSELRAD, 2011). Dessa forma, os critérios de Equidade Ambiental procuram garantir uma proteção equânime aos grupos sociais atingidos pelas consequências indesejadas dos empreendimentos econômicos utilizadores de bens ambientais, partindo do pressuposto de que os mecanismos convencionais de impacto ambiental provocam consequências sociais, econômicas e ambientais negativas para as comunidades locais.

Desse modo, diferentemente do que ocorre com a Avaliação de Impactos Ambientais (AIA), que muitas vezes tende a minimizar a presença de populações nas áreas nas quais empreendimentos serão instalados, desconsiderando-se, por conseguinte, toda a história da relação dos grupos com o território, seus aspectos simbólicos, morais e afetivos, a AEA evidencia que os aspectos ambientais não podem ser avaliados sem que se leve em consideração as demais dimensões do meio ambiente que enaltecem o aspecto social.

A partir dessa abordagem, vem-se discutindo a construção de processos e instrumentos de AEA que, ao incorporarem os critérios e a perspectiva dos grupos sociais potencialmente atingidos, tragam para o campo de análise e avaliação de impacto também os efeitos sociais, culturais, econômicos e institucionais dos projetos de desenvolvimento (RIGOTTO, 2009).

Por isso, a AEA pode redundar, inclusive, na suspensão de determinados empreendimentos, opção praticamente nula, porque nela o empreendimento nasce inevitável, e surge da noite para o dia no horizonte dos grupos sociais locais, pelo que se coloca como necessidade premente uma reflexão acerca da liberdade locacional proporcionada ao capital para suas investidas, com as condições necessárias a sua viabilização garantidas pelo Estado, redundando-se, assim, por impossibilitar contingências de caráter social, ecológicas, étnico-culturais, dentre outras, direcionadoras de outra perspectiva de desenvolvimento (PORTO, 2005). Há a predominância, portanto, de um discurso em que as formas de apropriação dos recursos naturais, a partir de uma lógica mercantil, são consideradas mais legítimas que outros diversos usos dados ao meio ambiente pelas populações que dele dependem para sua reprodução material e simbólica. 
Os preceitos que fundamentam a Equidade Ambiental são o tratamento justo, para que nenhum grupo venha a arcar de maneira desproporcional com as consequências ambientais negativas de determinado projeto, e o envolvimento efetivo, que se dá pela possibilidade de participação nas etapas nas quais irá passar o projeto, desde a sua concepção no planejamento, até o processo de tomada de decisão, com os seus desdobramentos, sendo importante ressaltar que, para que os atingidos participem efetivamente, devem ter acesso às informações sobre o projeto.

0 modelo atualmente existente de AEA abarca os preceitos acima citados, propondo-se a complementar os estudos ambientais que, por força da legislação, devem ser realizados, constituindose numa proposta alternativa de avaliação socioambiental (ACSELRAD, 2011).

Pelo exposto, tem-se que a concretização da Equidade Ambiental ocorre quando se consegue incorporar a percepção dos grupos sociais vulneráveis, potencialmente os mais atingidos pelos projetos da hegemonia econômica utilizadores dos bens ambientais, valorizando-se, em análise última, a participação social.

\section{COMUNIDADE E TUTELA DO MEIO AMBIENTE}

A Tutela Constitucional do Meio Ambiente encontra a sua base normativa direta consubstanciada no art. 225, com seus parágrafos e incisos (BRASIL, 2012). 0 caput do art. 225 estabelece que "Todos têm direito ao meio ambiente ecologicamente equilibrado, bem de uso comum do povo e essencial à sadia qualidade de vida, impondo-se ao poder público e à coletividade o dever de defendê-lo e preserválo para as presentes e futuras gerações" (BRASIL, 2012, p. 127). Assim, ao prevê que "todos têm direito ao meio ambiente ecologicamente equilibrado" (BRASIL, 2012, p. 127), o qual é tido como "essencial à sadia qualidade de vida" (BRASIL, 2012, p. 127), é possível concluir que a proteção ao meio ambiente é pressuposto para que se atenda um valor constitucional fundamental: a vida; logo, o direito ao meio ambiente equilibrado também se configura como um direito fundamental, e, portanto, intransigível.

Outra importante conclusão também daí oriunda é a de que a defesa e a preservação do meio ambiente devem ser feitas não apenas pelo poder público, mas igualmente pela coletividade, pelo que deixa o cidadão de ser um mero titular de direito, passando, inclusive, a ter um dever, o que traduz a ideia de que, para encaminhamentos e resoluções das questões que envolvam o meio ambiente, especial ênfase deve ser dada a cooperação entre Estado e sociedade (MILARÉ, 2013). Assim, estabelecendo um elo entre a AEA e a participação social, tem-se que o envolvimento efetivo é um dos elementoschave para a realização de uma avaliação ambiental comprometida com critérios de equidade.

Dessa forma, a partir da década de 1980, com a redemocratização que foi ocorrendo no país, passou-se a abrir mais espaço para as comunidades expressarem-se quanto às questões ambientais, paulatinamente ocorrendo, na sociedade e no governo, a internalização da necessidade do tratamento das questões ambientais com as populações afetadas. Nesse sentido, Milaré (2013) defende a ideia de que a participação comunitária no processo político-administrativo é legítima e eficaz.

0 referido autor também indica alguns meios de participação popular quanto à tutela ambiental: (i) participação no processo legislativo, com a propositura de projetos de lei, ou realização de referendo 
sobre uma lei relacionada com o meio ambiente, na forma detalhada na CF/88; (ii) participação em órgãos colegiados dotados de poderes normativos, que diz respeito a presença de representantes da comunidade nos conselhos e órgãos de defesa ambiental; (iii) participação na formulação e execução de políticas ambientais, entendidas elas como as opções políticas feitas pelo poder público, as quais envolvem o destino e a utilização dos bens ambientais, sendo que, nesse meio, a participação popular tem sido mais deficiente, seja pela ausência de contato direto da comunidade com a administração pública, seja por falta de composição paritária nos órgãos colegiados que estão incumbidos dessas políticas; aqui se inserem as denominadas audiências públicas; participação popular através do Poder Judiciário, visto que a CF/88 assegurou ao cidadão, em várias possibilidades, à defesa judicial do meio ambiente, como, por exemplo, pela propositura de ação civil pública, no art. 129 , inciso III, c/c o § $1^{\circ}$ (MILARÉ, 2013, p. 215 - 217).

O nomen juris de um importante meio viabilizador do direito da comunidade de participar das políticas públicas ambientais é audiência pública, como já destacado. A audiência pública está regulamentada na Resolução CONAMA n ${ }^{\circ}$ 9/1987, que indica quatro possibilidades de convocação: ( $1^{\mathrm{a}}$ ) quando o órgão ambiental julgar necessário; $\left(2^{\mathrm{a}}\right)$ por solicitação de entidade civil; $\left(3^{\mathrm{a}}\right)$ por solicitação do Ministério Público e ( $\left.4^{\mathrm{a}}\right)$ a pedido de 50 (cinquenta) ou mais cidadãos, encontrado no art. $2^{\circ}$, caput (BRASIL, 1990b).

É importante destacar também que, de acordo com o art. $2^{\circ}$ e $\S 2^{\circ}$ da Resolução CONAMA ${ }^{\circ}$ 9/1987, em existindo solicitação de quaisquer dos legitimados acima indicados, e não havendo a audiência pública, "a licença não terá validade" (BRASIL, 1990b, p. 643). Nesse contexto, a audiência pública é um importante instrumento de gestão do meio ambiente. Dessa forma, as audiências públicas estão inseridas no EIA como um de seus momentos de desdobramento, de acordo com o art. $3^{\circ}$ da resolução CONAMA n 237/1997 (BRASIL, 1997). Contudo, muitas vezes têm servido para divulgar o empreendimento, em detrimento do amplo debate sobre os seus reais impactos socioambientais, bem como também se observa.

Tais constatações, que corroboram a abordagem da distribuição desigual dos males ambientais, devem ser combatidas, pois, como abordado, as diversas formas de participação da comunidade interessada, além de necessárias a uma completa e eficiente gestão ambiental, estão garantidas legalmente, por isso, devem ocorrer de forma ativa, o que requer o conhecimento dos fatos, quer dizer, o acesso amplo à informação verdadeira, para que a mesma comunidade possa minimamente se posicionar diante deles.

\section{CONSIDERAÇÕES FINAIS}

Apesar do Movimento por Justiça Ambiental, do ponto de vista dos riscos ambientais para as populações mais vulneráveis, a Justiça Ambiental não tem sido respeitada pelos grandes empreendimentos econômicos e nem figura tal como se apresenta em lei na gestão ambiental por parte do Poder Público, seja nos Estados Unidos, seja nos demais países, porque a distribuição dos danos 
ambientais se concentra junto às minorias étnicas e as parcelas excluídas da sociedade global. Ao contrário, mesmo ao se admitir que os conflitos ambientais correspondem às contradições inerentes aos diversos segmentos sociais em luta pela gestão ambiental do território, assume-se a existência de uma proteção ambiental desigual e o Estado cria ou autoriza projetos de desenvolvimento econômico e, baseado no viés economicista, ao invés de mediar os conflitos ambientais entre os diversos atores sociais direta ou indiretamente atingidos, por meio de regras e limites aceitos pela coletividade, colocase ao lado dos grandes grupos empresariais que aumentam os danos ambientais às classe sociais mais pobres e às minorias étnicas.

Por outro lado, previsto em lei nos casos de empreendimentos potencialmente poluidores ou que causem degradação ambiental, o Licenciamento Ambiental no Brasil, somado a AIA, o PNMA e às Resoluções do CONAMA, são instrumentos jurídicos indispensáveis à prevenção, correção, mitigação e/ou compensação dos riscos e impactos ambientais, embora os resultados de tais leis de proteção ambiental não sejam vislumbrados na prática.

Porém, no caso da AIA, os danos e conflitos ambientais promovidos por uma visão de meio ambiente eminentemente tecnicista, que não considera a multidimensionalidade em termos culturais, políticos e, sobretudo, sociais, é superada pela AEA, isto é, por uma forma de apreensão dos recursos naturais que vislumbre a participação das comunidades locais atingidas bem como às desigualdades na distribuição dos riscos ambientais.

A propósito, a garantia legal da Tutela do Meio Ambiente ao Poder Público e, principalmente, à coletividade representa um avanço jurídico para a preservação e conservação dos recursos naturais. Nesse sentido, urge a cooperação entre Estado e sociedade, sendo que os mecanismos para isso já foram criados.

Cumpre destacar que, se existem tantos avanços em relação à legislação e às normas para a garantia da gestão ambiental do território mais justa e democrática em nosso país, ainda não se verificou a superação dos recursos naturais com base na distribuição desigual dos danos ambientais e a redução dos conflitos ambientais, particularmente para as camadas sociais mais pobres e minorias. A esse respeito, há necessidade de pesquisas novas que investiguem essas lacunas e questões relativas à dicotomia entre a teoria e a prática no âmbito da gestão ambiental do território.

Nesse bojo, urge a adoção de um paradigma novo, holístico e complexo, capaz de substituir a abordagem da gestão ambiental apenas do ponto de vista tecnicista e instrumental. Em outras palavras, pesquisas científicas, planos, programas e projetos capazes de compreender a gestão ambiental como instrumento que, ao valorizar a participação dos mais vulneráveis e minorias, atenda aos interesses da coletividade, levando em consideração a dimensão social, cultural, política, geográfica e simbólica para a intervenção no meio ambiente, e não simplesmente a econômica, o que reduzirá os males ambientais às parcelas mais vulneráveis de nossa sociedade.

Da mesma forma, a reformulação do paradigma economicista, na medida em que o crescimento econômico deve ser limitado e controlado pelas dimensões social e ecológica, havendo também a necessidade de o canalizar para as áreas do serviço público, tais como a saúde, a educação e os 
transportes. Além disso, o crescimento econômico, que tem apelo ao consumo de bens materiais, deve se voltar para o crescimento espiritual e interior, cooperação e justiça social, ao invés de ser baseado somente nos valores da competição, individualismo, lucro, eficiência, produção e consumo de bens materiais. Logo, há a confusão entre padrão de vida, ligado mais ao consumo de bens materiais, e qualidade de vida, a qual engloba a melhoria das condições socioeconômicas e ambientais.

Mais do que uma crise ambiental que fundamente o crescimento da demanda energética de fontes alternativas de energia, particularmente a energia eólica, o que vivenciamos é uma crise de valores, atitudes e estilos de vida, a qual conduz a reflexão em torno de práticas sociais vinculadas ao paradigma novo mais holístico e profundo na apreensão dos fenômenos. Dito de outro modo, há necessidade de uma mudança rumo a uma visão de mundo mais complexa, multidimensional e ecológica, a qual seja incorporada pelo Estado diante da comunidade de entorno aos grandes empreendimentos, especialmente os parques eólicos, no sentido de viabilizar a Justiça Ambiental, reduzir os conflitos ambientais e criar uma verdadeira equidade ambiental que leve em consideração as comunidades de entorno mais vulneráveis e atingidas do ponto de vista socioeconômico e ambiental pelas grandes corporações econômico-financeiras.

\section{REFERÊNCIAS}

1. ACSELRAD, H. Introdução. In: LEROY, J. P. et al. Relatório-síntese projeto avaliação de equidade ambiental como instrumento de democratização dos procedimentos de avaliação de impacto de projetos de desenvolvimento. Rio de Janeiro: FASE/ETTERN/IPPUR, 2011, p. 41-69. Disponível em: $<$ https://fase.org.br/wp-content/uploads/2011/07/Relat\%C3\%B3rio+-+S\%C3\%ADntese+-+Projeto+Aval iacao+Equidade+Ambiental+final.final_.pdf>. Acesso em: 28 nov. 2015.

2. ACSELRAD, H. et al. $\mathbf{0}$ que é justiça ambiental. Rio de Janeiro: Garamond, 2009.

3. BARACUHY, J. G. V. Manejo integrado de micro bacias hidrográficas no semiárido nordestino: estudo de um caso. 2001. Tese (Doutorado em Recursos Naturais)-Universidade Federal de Campina Grande, Campina Grande, 2001.

4. BOBBIO, N.; MATTEUCCI, N.; PASQUINO, G. Conflito. In: Dicionário de política. 11 ed. Brasília: Editora Universidade de Brasília, 1992. v. 1. p. 228.

5. BRASIL. Constituição (1988). Constituição da República Federativa do Brasil: texto constitucional promulgado em 5 de outubro de 1988, com as alterações adotadas pelas emendas Constitucionais $n$. $^{\circ} 1 / 1992$ a $68 / 2011$, pelo Decreto legislativo $n^{\circ} 186 / 2008$ e pelas emendas Constitucionais de Revisão nos 1 a 6/1994. 35. ed. Brasília: Câmara dos Deputados, Edições Câmara, 2012. Disponível em: < http://bd.camara.gov.br/bd/bitstream/handle/bdcamara/15261/constituicao_ federal_35ed.pdf?sequence=9>. Acesso em: 10 out. 2016.

6. Decreto $n^{\circ}$ 99.274, de 6 de junho de 1990a. Dispõe sobre a criação de Estações Ecológicas e Áreas de Proteção Ambiental e sobre a Política Nacional do Meio Ambiente, e dá outras providências. Diário Oficial [da] República Federativa do Brasil, Brasília, v. 128, n. 109, p. 
1-5, 7 jun. 1990a. Seção 1. Disponível em: <http://pesquisa.in.gov.br/imprensa/jsp/visualiza/index. jsp?data=07/06/1990\&jornal=1\&pagina=1\&totalArquivos=160>. Acesso em: 25 out. 2016.

7. L Lei complementar $n^{0} 140$, de 8 de dezembro de 2011. Fixa normas para a cooperação entre a União, os Estados, o Distrito Federal e os Municípios nas ações administrativas decorrentes do exercício da competência comum relativas à proteção das paisagens naturais notáveis, à proteção do meio ambiente, ao combate à poluição em qualquer de suas formas e à preservação das florestas, da fauna e da flora. Diário Oficial [da] República Federativa do Brasil, Brasília, v. 148, n. 236, p. 1-3, 9 dez. 2011. Seção 1. Disponível em: <http://pesquisa.in.gov.br/imprensa/jsp/visualiza/index. jsp?data=09/12/2011\&jornal=1\&pagina=1\&totalArquivos=208>. Acesso em: 20 out. 2016.

8. - Lein ${ }^{\circ} 6.938$, de 31 de agosto de 1981. Dispõe sobre a Política Nacional do Meio Ambiente, seus fins e mecanismos de formulação e aplicação, e dá outras providências. Diário Oficial [da] República Federativa do Brasil, Brasília, v. 119, n. 167, p. 1, 2 set. 1981. Seção 1. Disponível em: < https://www. jusbrasil.com.br/diarios/3461466/pg-1-secao-1-diario-oficial-da-uniao-dou-de-02-09-1981/pdfView>. Acesso em: 15 out. 2016.

9. - Ministério do Meio Ambiente. Conselho Nacional de Meio Ambiente. Resolução nº 9, de 3 de dezembro de 1987. Dispõe sobre a realização de Audiências Públicas no processo de licenciamento ambiental. Diário Oficial [da] República Federativa do Brasil, Brasília, v. 128, n. 128, p. 7, 5 jul. 1990b. Seção 1. Disponível em: < http://pesquisa.in.gov.br/imprensa/jsp/visualiza/index. jsp?data=05/07/1990\&jornal=1\&pagina=7>. Acesso em: 10 nov. 2016.

10. Ministério do Meio Ambiente. Conselho Nacional de Meio Ambiente. Resolução n 237, de 19 de dezembro de 1997. Dispõe sobre a revisão e complementação dos procedimentos e critérios utilizados para o licenciamento ambiental. Diário Oficial [da] República Federativa do Brasil, Brasília, v. 237, n. 247, p. 30.841-30.843, 22 dez. 1997. Seção 1. Disponível em: <http://www.in.gov.br/ mp_leis/ leis_texto.asp?ld=LEl\%209887>. Acesso em: 22 nov. 2016.

11. Supremo Tribunal Federal. Medida Cautelar na Ação Direta de Inconstitucionalidade $\mathbf{n}^{\circ}$

3.540, de 1 de setembro de 2005. Disponível em: < http://www.stf.jus.br/imprensa/pdf/adi3540ementa. pdf>. Acesso em: 1 nov. 2016.

12. BROWN, L. R. Buüding a Sustainable Society. Nova York: Norton, 1981.

13. CAPRA, Fritjof. 0 ponto de mutação. São Paulo: Cultrix, 2006.

14. CARTIER, R. et al. Vulnerabilidade social e risco ambiental: uma abordagem metodológica para avaliação de injustiça ambiental. Cadernos de Saúde Pública, Rio de Janeiro: v. 25, n. 12, p. 2.695-2.704, dez. 2009.

15. COSTANZA, R. Ecological economics: the science and management of sustainability. New York: Columbia Press, 1991.

16. FIORILLO, C. A. P. Curso de Direito Ambiental Brasileiro. 9. ed. São Paulo: Saraiva, 2008.

17. GOLDSMITH, E. et al. Blueprint for survival. Boston: Penguin, Harmondsworth \& Houghton Mifflin, 1972.

18. JACKSON, T. Prosperidade sem crescimento: vida boa em um planeta finito. São Paulo: Editora 
Planeta Sustentável. 2013.

19. LEFF, Enrique. Racionalidade ambiental: a reapropriação social da natureza. Rio de Janeiro, Civilização Brasileira, 2006.

20. LEUZINGER, M. D.; CUREAU, S. Direito ambiental. Rio de Janeiro: Essevier, 2013.

21. LÖWY, M. "Por um novo mundo, sem capitalismo". Revista Caros Amigos, São Paulo, 16 dez. 2015. Disponível em: < http://www.carosamigos.com.br/index.php/grandes-entrevistas/5756entrevista-michael-loewy>. Acesso em: 1 jun. 2017.

22. MARX, K. O processo de produção do Capital. In: O capital: crítica da economia política. 23 ed. Rio de Janeiro: Civilização Brasileira, 2006. v.1.

23. MILARÉ, É. Direito do ambiente: doutrina, jurisprudência, glossário. 8. ed. São Paulo: Revista dos Tribunais, 2013.

24. MUNASINGHE, M.; MCNEELY, J. Keys concepts and terminology of sustainable development. In: Munasinghe, M.; Shearer, W. (ed.). Defining and measuring sustainability: the biogeobiophysical foundations. Washington, D.C.: The United Nations University \& The World Bank, 1995.

25. PORTO, M. F. de S. Saúde do trabalhador e o desafio ambiental: contribuições do enfoque ecossocial, da ecologia política e do Movimento pela Justiça Ambiental. Ciência \& Saúde Coletiva, Rio de Janeiro: v. 10, n. 4, p. 829 - 839, out./nov. 2005.

26. PRONK, J.; ul HAQ, M. Sustainable development: from concept to action. New York: United Nations Development Programme, 1992.

27. QUINTAS, J. S. Introdução à gestão ambiental pública. 2. ed. Brasília: IBAMA, 2006. (Coleção Meio Ambiente. Série Educação ambiental, 5). Disponível em: <http://www.icmbio.gov.br/ educacaoambiental/images/stories/biblioteca/educacao_ambiental/QUINTAS_Jos\%C3\%A9_Silva_-Introdu\%C3\%A7\%C3\%A3o_\%C3\%A0_Gest\%C3\%A3o_Ambiental_P\%C3\%BAblica.pdf>. Acesso em: 5 abr. 2016.

28. RIGOTTO, R. M. Inserção da saúde nos estudos de impacto ambiental: o caso de uma termelétrica a carvão mineral no Ceará. Ciência \& Saúde Coletiva, Rio de Janeiro: v. 14, n. 6, p. 2.049 - 2.059, dez. 2009.

29. SANTOS, A. N. G. A energia eólica no litoral do NE no Brasil: desconstruindo a "sustentabilidade" para promover "justiça ambiental". Rio de Janeiro: [s.n.], 2014. Disponível em: <https://br.boell.org/ptbr/2014/11/07/energia-eolica-no-litoral-do-ne-no-brasil>. Acesso em: nov. 2015.

30. SILVA, J. A. da. Direito ambiental constitucional. São Paulo: Malheiros Editores, 2009.

31. SIRVINSKAS, L. P. Manual de direito ambiental. 7. ed. São Paulo: Saraiva, 2009. 